\title{
Solving the Capacitated Vehicle Routing Problem in a Shared Bicycle System of a Smart City
}

\author{
Edgar Gonzalo Cossio Franco ${ }^{1}$, Alberto Ochoa-Zezzatti ${ }^{2}$, \\ José Alberto Hernández ${ }^{3}$ Aguilar, Julio Ponce Gallegos ${ }^{4}$ \\ ${ }^{1}$ Universidad Enrique Díaz de León, Guadalajara, Jalisco, \\ Mexico \\ ${ }^{2}$ Universidad Autónoma de Ciudad Juárez, Chihuahua, \\ Mexico \\ ${ }^{3}$ Universidad Autónoma del Estado de Morelos, Morelos, \\ Mexico \\ ${ }^{4}$ Universidad Autónoma de Aguascalientes, Aguascalientes, \\ Mexico \\ kofrran@gmail.com, alberto.ochoa@uacj.mx, \\ \{alberto_doctor, julk_cpg\}@ hotmail.com
}

\begin{abstract}
A shared bicycle system (SBC) is a set of elements that compose an ecosystem in which a user travels in relatively short traverses from one point to another and their trajectory times are improved, exercised and treated of nonmotorized vehicles, no Contaminates the environment. This ecosystem consists of bicycles, geographically distributed stations (ports), a card-charging system. In the present investigation with respect to the problem of Vehicle Routing with Capacity (CVRP) to determine a better route. MATLAB was used for the implementation of the CVRP algorithm. As a result, an improvement in the distribution of bicycles in the ports is shown.
\end{abstract}

Keywords: smart city, shared bicycle system, MATLAB, CVRP.

\section{$1 \quad$ Introduction}

Smart city is defined as that which intelligently integrates economy, people, mobility, the environment, government and sustainability [1]. In the case of the present investigation will focus the attention in the branch of the mobility since it is by means of which the (SBC), is specified. Figure 1 shows the mobility ecosystem of a smart city.

Within the mobility block there is a great concern to project more efficient plans of displacement of the people known as Sustainable Urban Mobility Plans (SUMP) whose objective is to align each of the blocks to guarantee a better quality of life of the people [2]. 


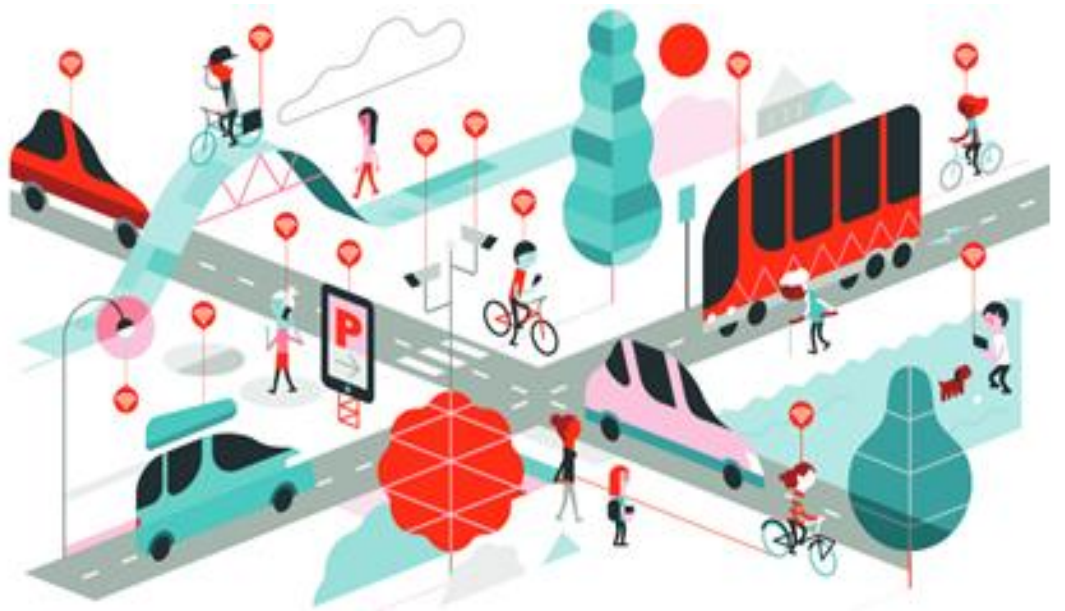

Fig. 1. Smart city ecosystem.

The National Institute of Statistics and Geography (INEGI For its acronym in Spanish), considers as of 2015 in its intercensal survey to the bicycle as a means of transfer to the place of work [3]; For Jalisco, eight indicators were captured in the survey; A) Truck, taxi, bus or bus, b) Truck, taxi, bus or bus, c) Private vehicle, d) Work transport, e) Bicycle, f) Walking, g) Other and h) Not specified. Figure 2 shows the percentages by which people move to their place of work. In total, the survey found that in Jalisco 2,854,085 people use some means to move to their place of work.

Under this scheme, considering that 5.46 is equivalent to 155,833 people using bicycles to go to their place of work then it is speaking that the fact of having a SBC is of vital importance to respond to the demand of citizenship.

The Capacitated Vehicle Routing Problem (CVRP), derives from the Vehicle Routing Problem (VRP); Was created by G. B. Dantzig and J. H. Ramser and the objective is to establish a strategy where cars to decrease the consumption of gasoline [4], as well as the distance between points that visit the agent during its travel along the path of distribution. Figure 3 shows the VRP.

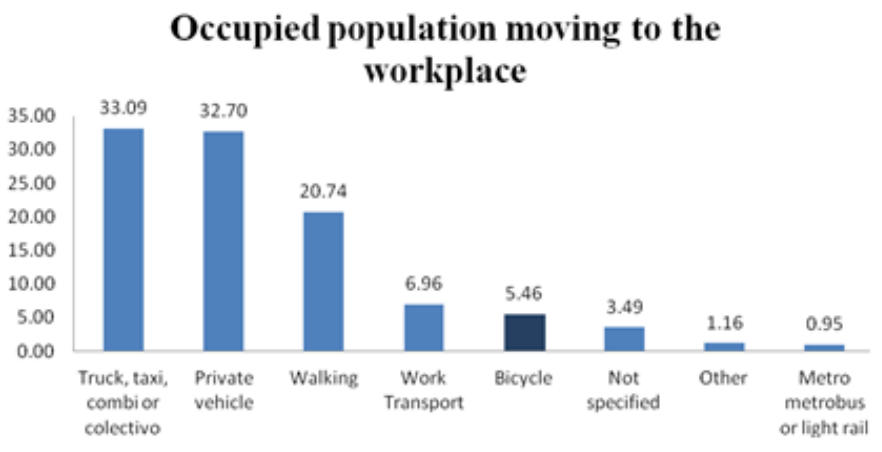

Fig. 2. Type of transport. 


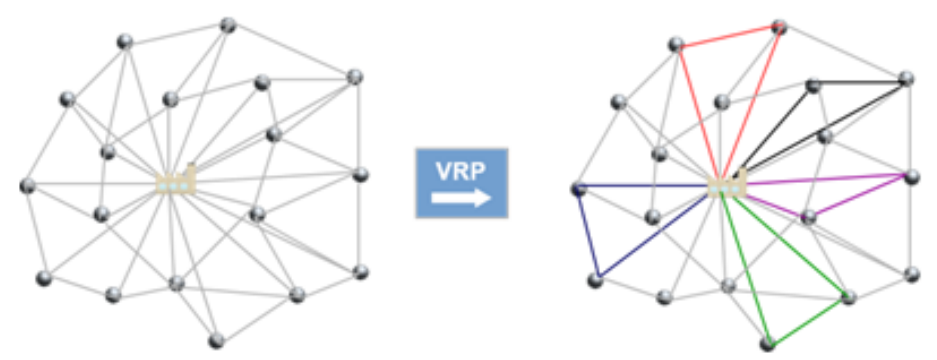

Fig. 3. The VRP.

An SBC can be modeled as in CVRP since they have identified the control points, load, discharge and step frequencies.

The VRP could be used but it was decided to use the variation with capacities (CVRP) since only the VRP is in charge of ensuring that all the points in a route are visited at least once. In the case of the present investigation, there is the variant of capacity and load per unit from point to point.

The mathematical model of the CVRP is shown below [13]:

$$
\begin{gathered}
\sum_{i \in V} \sum_{j \in V} c_{i j} x_{i j} \\
\sum_{i \in V} x_{i j}=1 \quad j \in V \backslash\{0\} \\
\sum_{j \in V} x_{i j}=1 \quad i \in V \backslash\{0\} \\
\sum_{i \in V} x_{i 0}=K \\
\sum_{j \in V} x_{o j}=K \\
x_{i j} \in\{0,1\} \quad \mathrm{i}, \mathrm{j} \in V \\
\sum_{i \in S} \sum_{j \in S} x i j \geq r(S), \quad \forall S \subset V \backslash\{0\}, \quad S \neq \phi
\end{gathered}
$$

\section{Description of the Problem}

The present research focuses on the city of Guadalajara, Jalisco, which is considered the first smart city in the world since 2013 [5]. There are four more in the world: Wuxi in China, Trento in Italy, Casablanca in Morocco and Kansas City in the United States.

Despite the benefits of the smart city ecosystem, there are areas of opportunity for further improvement because, as new paradigms are concerned, the ecosystem cannot yet be considered an axiom. 
Among the problems encountered in an SBC, specifically in the mobility block, it is found that when the user arrives at a station he expects to always find a unit available to take and move to his destination; Usually what happens is that the stations are limited to 10 to 18 bicycles, depending on the geographic location of the station as it is located, it is the demand for example the number of units that are destined in the station of the center Of the city with respect to one that is in the periphery, where the quantity is smaller.

In that scenario the user must wait for a new unit to arrive or move to another nearby station. Another problem that is detected is the maintenance of the units derived from wear and tear by natural use. As long as it is possible to identify routes where the units are less traveled in terms of mileage, it will be possible to prolong the units in good condition.

Figure 4 shows the points and the flow of the SBC that represent the complete route of [6] for Guadalajara in 2015.

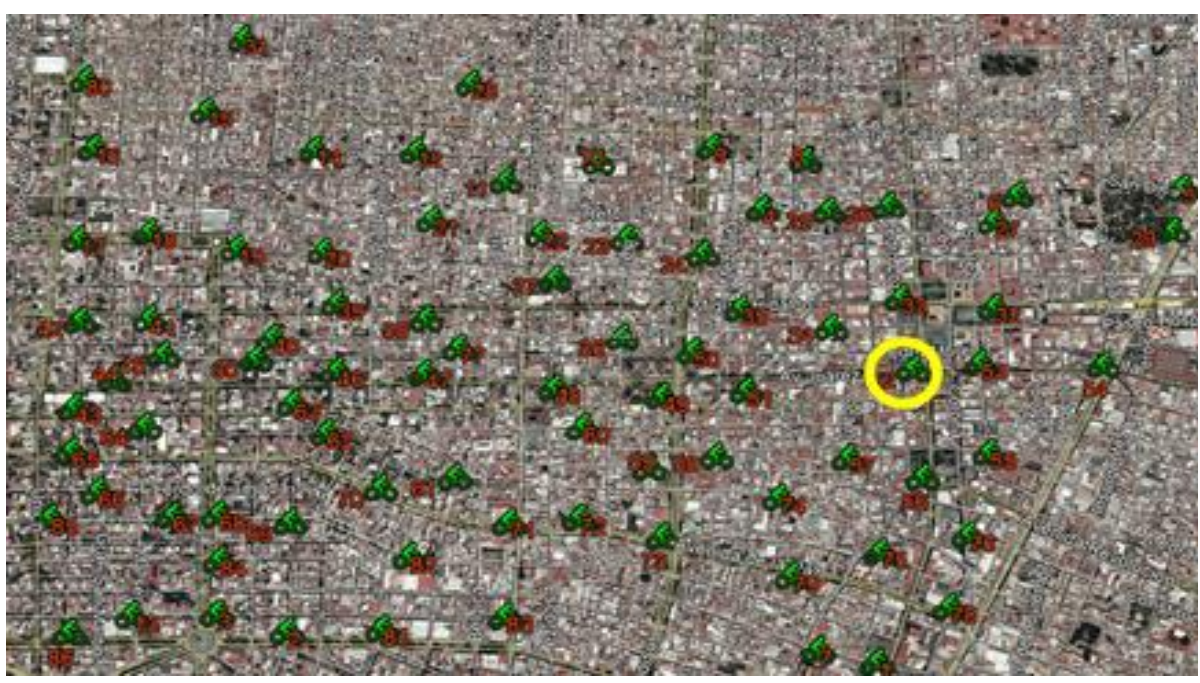

Fig. 4. SBC path.

From the complete route shown in Figure 4, there are 86 points in total, in what is known as the first square of the city, the points go from Calzada Independencia to Avenida Union and from Manuel Acuña to Avenida Niños Heroes.

The VRP is a problem of Nonlinear Programming but its combinatorial nature and characteristics can be represented by a graph and on that basis describe the objective function and restrictions.

Given a graph $\mathrm{G}(\mathrm{V}, \mathrm{E})$ where $\mathrm{V}$ is the vertexes set and $\mathrm{E}$ is the edges set, the VRP is formulated as follows:

$\mathrm{V}=\{\mathrm{v} 0, \mathrm{v} 1, \ldots, \mathrm{vn}\}$ is a vertexes set, where:

$\mathrm{v} 0$ is considered as a depot.

And $\mathrm{V}^{\prime}=\mathrm{V} \backslash\{\mathrm{v} 0\}$ be used as the set of $\mathrm{n}$ costumers. 
$A=\{(v i, v j) \mid v i, v j \mathrm{~V} ; \mathrm{i} j\}$ is an arc set

$\mathrm{C}$ is a matrix of costs (positives) or distances cij between customers vi and vj.

$\mathrm{d}$ is a vector of the customer demands.

$\mathrm{Ri}$ is the route for vehicle $\mathrm{i}$

$\mathrm{m}$ is the number or vehicles with the same characteristics. One route is assigned to each vehicle.

When the problem is symmetric, it means, cij=cji for all (vi, vj) $A$, then $E=\{(v i, v j) \mid$ vi, vj

$\mathrm{V} ; \mathrm{i}<\mathrm{j}\}$.

With each vertex vi in $V^{\prime}$ is associated a quantity qi of some goods to be delivered by a vehicle. The VRP thus consists of determining a set of $m$ vehicle routes of minimal total cost, starting and ending at a depot, such that every vertex in $\mathrm{V}^{\prime}$ is visited exactly once by one vehicle. For easy computation, it can be defined $b(\mathrm{~V})=[(\Sigma v i \mathrm{v}$ di) $/ \mathrm{C}]$, an obvious lower bound on the number of trucks needed to service the customers in set V. If is considered a service time $\partial \mathrm{i}$ (time needed to unload all goods), required by a vehicle to unload the quantity qi at vi. It is required that the total duration of any vehicle route (travel plus service times) may not surpass a given bound D, so, in this context the cost cij is taken to be the travel time between the cities. The VRP defined above is NP-hard. The feasible solution of it can be represented as follows:

a partition $\mathrm{R} 1, \ldots, \mathrm{Rm}$ of $\mathrm{V}$; and

a permutation $\sigma \mathrm{i}$ of $\mathrm{Ri} \mathrm{U} 0$ specifying the order of the customers on route $\mathrm{i}$.

The cost of a given route $(\mathrm{Ri}=\{\mathrm{v} 0, \mathrm{v} 1, \ldots, \mathrm{vm}+1\})$, where vi $\mathrm{V}$ and $\mathrm{v} 0=\mathrm{vm}+1=0(0$ denotes the depot), is given by:

$$
\mathrm{C}\left(\mathrm{R}_{\mathrm{i}}\right)=\sum_{i=0}^{m} C_{i, i+1}+\sum_{i=1}^{m} \partial_{i}
$$

A route $\mathrm{Ri}$ is feasible if the vehicle stops exactly once in each customer and the total duration of the route does not exceed a pre-specified bound $\mathrm{D}: \mathrm{C}(\mathrm{Ri}) \leq \mathrm{D}$.

Finally, the cost of the problem solution $\mathrm{S}$ is:

$$
\mathrm{F}_{\mathrm{VRP}}(\mathrm{S})=\sum_{i=\mathbf{0}}^{m} C\left(R_{i}\right)
$$

\section{Related Work}

In [7], it is shown that efforts have been made in Singapore to support the rearrangement and distribution of bicycles. They argue that for this type of system (SBC), to be useful, the correct number of bicycles should be deployed in the right places, as this affects the rate of use of bicycles and how bicycles circulate within the system.

In [8], mechanisms based on multi-agent systems are proposed to identify the bicycle crossing points as well as better distribution of the same.

A work was done by [9], where the problem of shared bicycles with ACO was attacked. 
In [10], open data applied in Washington D.C. to the system of shared bicycles with the purpose of locating the terminals according to the best satisfaction of the users.

\section{The Proposal}

As part of the strategy of the present investigation to address the above problem is taken as a point of reference a port (52), of 86 (as shown in Figure 4). The geographical location of this point is 16 de Septiembre Av. (Alcalde) and Juárez Av. (Vallarta Av.) Figure 5 shows the point and in Figure 6 the depot is shown.

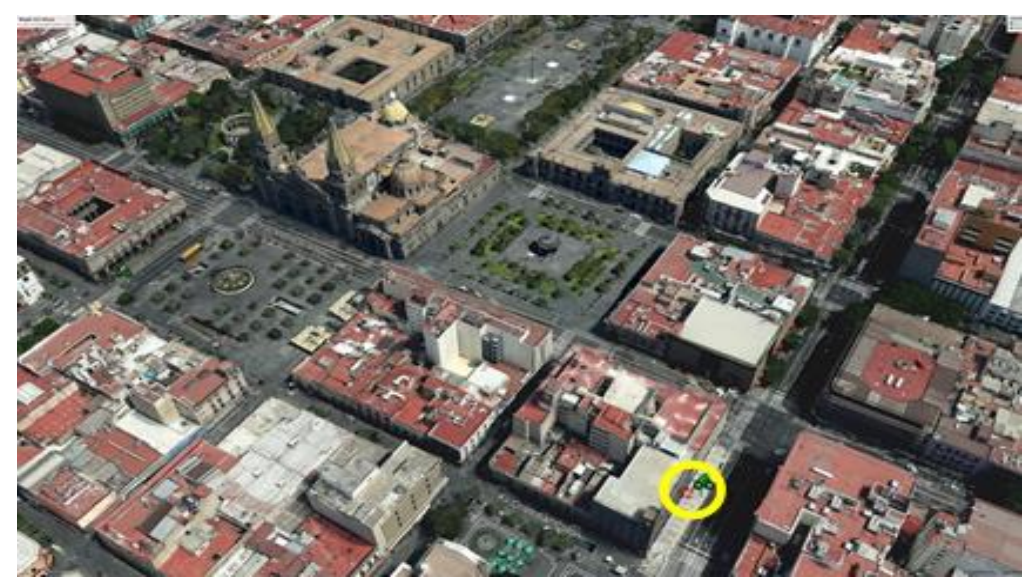

Fig. 5. Location of the port.

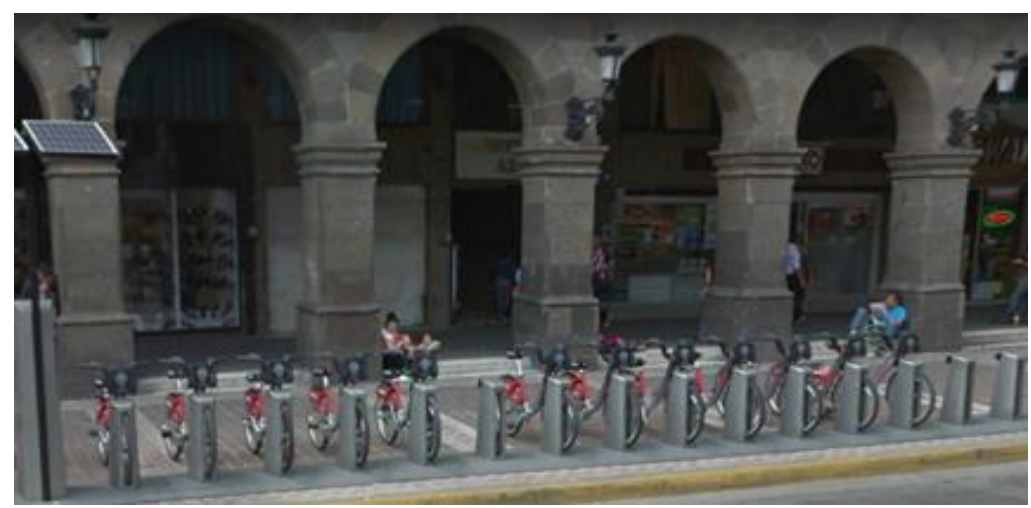

Fig. 6. Depot.

This port was chosen for being the most demanded of all the SBC according to their number of trips. According to [6], the total number of bicycles for this point is 16, while for other ports the total is between 8 and 10, according to their point of location and demand. In addition, the number of trips is higher, as shown in Table 1. 
Table 1. SBC.

\begin{tabular}{|c|c|c|}
\hline key & bikes & travels \\
\hline GDL-52 & 16 & 2054 \\
\hline GDL-48 & 10 & 2028 \\
\hline GDL-49 & 22 & 2020 \\
\hline GDL-50 & 16 & 1873 \\
\hline GDL-73 & 13 & 1830 \\
\hline GDL-32 & 10 & 1687 \\
\hline GDL-63 & 16 & 1679 \\
\hline GDL-54 & 16 & 1595 \\
\hline GDL-09 & 13 & 1510 \\
\hline GDL-19 & 10 & 1474 \\
\hline GDL-64 & 10 & 1468 \\
\hline GDL-56 & 10 & 1440 \\
\hline GDL-71 & 7 & 1424 \\
\hline GDL-61 & 10 & 1415 \\
\hline GDL-62 & 10 & 1335 \\
\hline GDL-84 & 13 & 1253 \\
\hline GDL-60 & 16 & 1162 \\
\hline GDL-65 & 10 & 1114 \\
\hline GDL-80 & 10 & 1093 \\
\hline GDL-36 & 13 & 1057 \\
\hline GDL-17 & 10 & 1020 \\
\hline GDL-15 & 10 & 1013 \\
\hline GDL-14 & 10 & 992 \\
\hline GDL-40 & 10 & 987 \\
\hline GDL-43 & 10 & 971 \\
\hline GDL-51 & 10 & 952 \\
\hline GDL-47 & 10 & 943 \\
\hline GDL-28 & 7 & 923 \\
\hline GDL-33 & 10 & 920 \\
\hline GDL-31 & 7 & 920 \\
\hline GDL-78 & 7 & 911 \\
\hline GDL-03 & 10 & 904 \\
\hline GDL-26 & 10 & 885 \\
\hline GDL-10 & 7 & 883 \\
\hline GDL-46 & 7 & 852 \\
\hline GDL-70 & 10 & 843 \\
\hline GDL-42 & 7 & 835 \\
\hline GDL-79 & 7 & 802 \\
\hline GDL-72 & 10 & 798 \\
\hline GDL-01 & 7 & 782 \\
\hline GDL-77 & 7 & 753 \\
\hline GDL-05 & 7 & 726 \\
\hline GDL-86 & 10 & 725 \\
\hline GDL-08 & 10 & 709 \\
\hline GDL-68 & 10 & 696 \\
\hline
\end{tabular}

\begin{tabular}{|l|l|l|}
\hline $\begin{array}{l}\text { key } \\
\text { GDL-25 }\end{array}$ & $\begin{array}{l}\text { bikes } \\
10\end{array}$ & $\begin{array}{l}\text { travels } \\
694\end{array}$ \\
\hline GDL-16 & 10 & 690 \\
\hline GDL-07 & 10 & 672 \\
\hline GDL-20 & 10 & 665 \\
\hline GDL-39 & 10 & 658 \\
\hline GDL-44 & 10 & 652 \\
\hline GDL-82 & 7 & 615 \\
\hline GDL-34 & 7 & 610 \\
\hline GDL-45 & 16 & 595 \\
\hline GDL-21 & 10 & 588 \\
\hline GDL-37 & 10 & 577 \\
\hline GDL-81 & 7 & 562 \\
\hline GDL-85 & 10 & 554 \\
\hline GDL-57 & 10 & 547 \\
\hline GDL-59 & 10 & 518 \\
\hline GDL-76 & 10 & 517 \\
\hline GDL-13 & 7 & 510 \\
\hline GDL-29 & 10 & 504 \\
\hline GDL-58 & 7 & 500 \\
\hline GDL-02 & 10 & 492 \\
\hline GDL-06 & 7 & 485 \\
\hline GDL-22 & 10 & 474 \\
\hline GDL-27 & 7 & 474 \\
\hline GDL-66 & 10 & 465 \\
\hline GDL-38 & 10 & 463 \\
\hline GDL-12 & 7 & 444 \\
\hline GDL-04 & 7 & 430 \\
\hline GDL-41 & 10 & 426 \\
\hline GDL-11 & 7 & 418 \\
\hline GDL-83 & 7 & 416 \\
\hline GDL-35 & 10 & 413 \\
\hline GDL-53 & 10 & 409 \\
\hline GDL-55 & 10 & 402 \\
\hline GDL-23 & 10 & 379 \\
\hline GDL-67 & 10 & 378 \\
\hline GDL-74 & 7 & 376 \\
\hline GDL-18 & 7 & 360 \\
\hline GDL-24 & 10 & 358 \\
\hline GDL-75 & 10 & 351 \\
\hline GDL-30 & 16 & 0 \\
\hline & & \\
\hline
\end{tabular}

Once the data set is identified, the trips are counted according to their location and thus a sample is created for the analysis of the behavior of the SBC. An analysis of the trips made by each user (with the objective of quantifying the trips per unit), is created the instance to solve the CVRP which is shown in Table 2. 
Table 2. Instance.

\begin{tabular}{|c|c|c|c|}
\hline $\mathbf{I d}$ & $\mathbf{X}$ & $\mathbf{Y}$ & $\mathbf{D}$ \\
\hline 1 & 61 & 65 & 2 \\
\hline 2 & 25 & 52 & 2 \\
\hline 3 & 56 & 41 & 3 \\
\hline 4 & 29 & 54 & 1 \\
\hline 5 & 44 & 48 & 2 \\
\hline 6 & 31 & 55 & 1 \\
\hline 7 & 48 & 42 & 1 \\
\hline 8 & 42 & 39 & 3 \\
\hline 9 & 47 & 36 & 1 \\
\hline 10 & 56 & 40 & 3 \\
\hline 11 & 56 & 40 & 3 \\
\hline 12 & 59 & 40 & 1 \\
\hline 13 & 56 & 51 & 1 \\
\hline 14 & 42 & 39 & 3 \\
\hline 15 & 27 & 61 & 3 \\
\hline 16 & 51 & 44 & 2 \\
\hline
\end{tabular}

\begin{tabular}{|c|c|c|c|}
\hline Id & $\mathbf{X}$ & $\mathbf{Y}$ & $\mathbf{D}$ \\
\hline 17 & 51 & 62 & 1 \\
\hline 18 & 50 & 70 & 1 \\
\hline 19 & 27 & 61 & 3 \\
\hline 20 & 25 & 52 & 2 \\
\hline 21 & 39 & 51 & 1 \\
\hline 22 & 48 & 53 & 1 \\
\hline 23 & 33 & 69 & 1 \\
\hline 24 & 69 & 54 & 1 \\
\hline 25 & 51 & 44 & 2 \\
\hline 26 & 38 & 66 & 1 \\
\hline 27 & 55 & 35 & 3 \\
\hline 28 & 55 & 35 & 3 \\
\hline 29 & 25 & 79 & 2 \\
\hline 30 & 25 & 79 & 2 \\
\hline 31 & 72 & 38 & 1 \\
\hline 32 & 42 & 39 & 3 \\
\hline
\end{tabular}

\begin{tabular}{|c|c|c|c|}
\hline Id & $\mathbf{X}$ & $\mathbf{Y}$ & $\mathbf{D}$ \\
\hline 33 & 45 & 48 & 2 \\
\hline 34 & 71 & 42 & 1 \\
\hline 35 & 55 & 35 & 3 \\
\hline 36 & 27 & 61 & 3 \\
\hline 37 & 61 & 65 & 2 \\
\hline 38 & 65 & 40 & 2 \\
\hline 39 & 65 & 40 & 2 \\
\hline 40 & 41 & 65 & 1 \\
\hline
\end{tabular}

Where Id is the identifier of each of the points, $\mathrm{X}, \mathrm{Y}$ are the location coordinates within the plane and $\mathrm{D}$ is the load of each of the points, which are determined by the instance obtained from the SBC. D is determined by the trips made to node 52 at a given time. Figure 7 shows the process of the proposal.

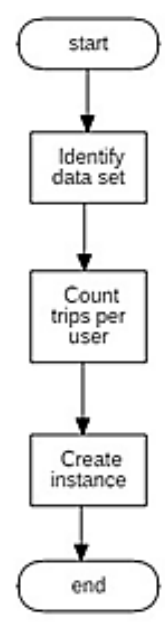

Fig. 7. Process.

\section{$5 \quad$ Methodology}

The process of Figure 7 is explained below. 
Identify data set. At this point the information analysis is performed; are located the busiest points and limits that covers the route as well as bicycles per point.

The point 52 of the set of nodes is identified given that it is the one that has the most affluence as shown in Table 1 with 2,054 trips in total.

Count trips per users. Once the set of data to be analyzed has been identified, a count is made of the users who go to what point to determine the most requested and at what time. Create instance. When the instance is created it is necessary to give it a format as shown in Table 2. Prior to the execution of the algorithm it is necessary to have an Id (node / ant), X (position $\mathrm{x}$ in the plane), $\mathrm{Y}$ (position $\mathrm{y}$ in the plane) and D (point-topoint loading).

For the implementation of this work we used the Nearest Neighbor Algorithm (NNA), algorithm proposed by Sas Wahid Hamzad [11].

The process to create the instance with the obtained data is observed in [12], where instances were compared to determine the optimal solution of given instances.

As part of the strategy, the points that make up the route are identified, which are shown in figure 8.

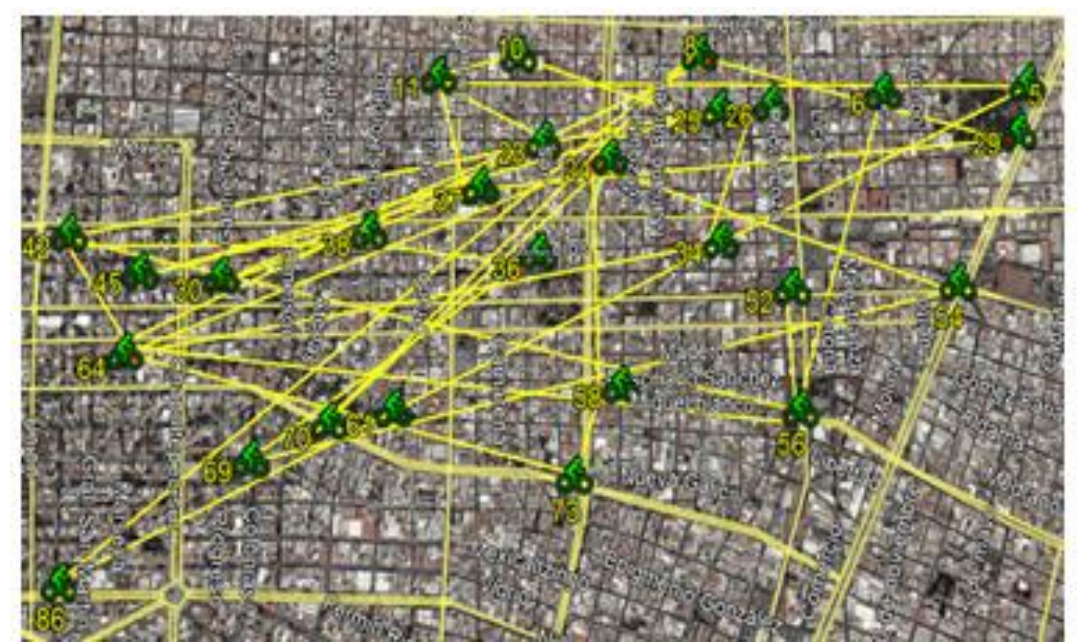

Fig. 8. The Grid.

Tracing the route is possible to identify a complete network in which the routes made by the units are long.

\section{$6 \quad$ Results}

The result is constructed from the execution of the algorithm in MATLAB from which the graph shown in Figure 9 is derived. Where each list represents the points that each bicycle is suggested to visit.

As the result of the execution of the algorithm with the instance, it was possible to distribute the points in two segments, the first one by visiting: 
Edgar Gonzalo Cossio Franco, Alberto Ochoa-Zezzatti, José Alberto Hernández Aguilar, et al.

$1>37>17>18>40>26>22>13>24>34>38>39>12>3>10>11>16>25>7>33>5>21>6$ $>4>15>23>1$

and the second by visiting:

$1>31>27>28>35>9>8>14>32>2>20>19>36>29>30>1$

The total area was $3.90 \mathrm{~km} 2$.

The result is shown in Figure 9.

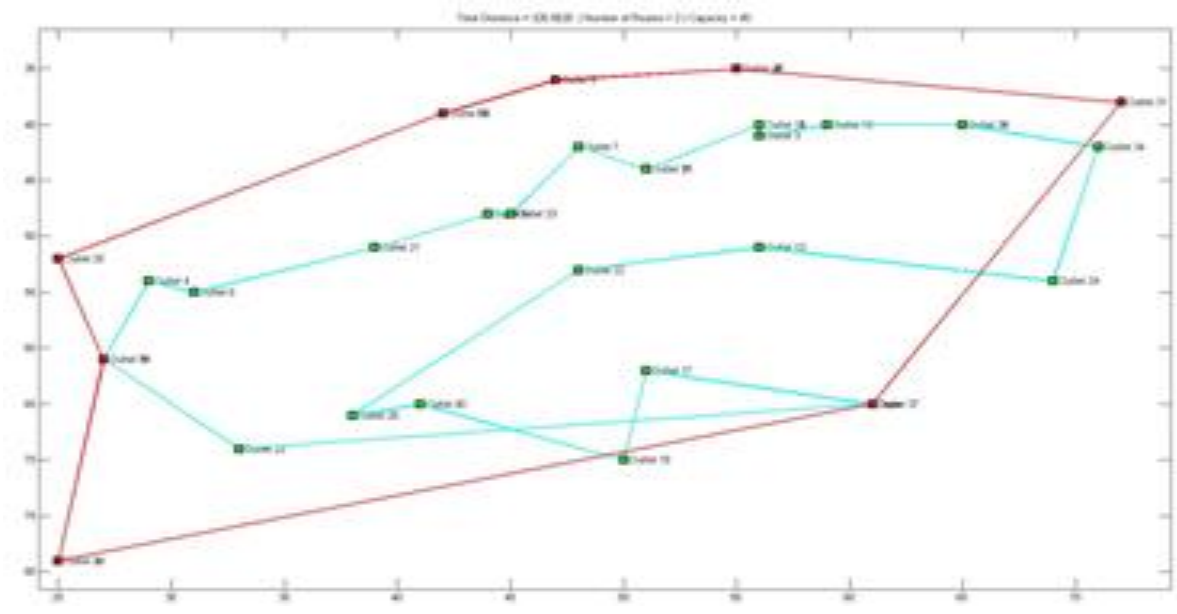

Fig. 9. Result.

\section{Conclusions}

After the experimentation of the present work, it is observed that through the application of computational techniques it is possible to improve a SBC in terms of distance and time and derived from it is possible to keep the units (bikes) in good condition since the lesser use is given to each one of them, the time of life is prolonged for more time.

\section{$8 \quad$ Future Work}

As a future work, it is proposed to submit the SBC instance to solve the CVRP in a parallel environment in order to observe the behavior of both schemes, that is, sequential and parallel.

It is also expected to be able to determine, by geo-positioning, safe routes according to crime rates. 


\section{References}

1. IEEE: http://smartcities.ieee.org/about.html (2017)

2. INNOPRO: http://www.innopro.es/pdfs/libro_blanco_smart_cities.pdf (2017)

3. INEGI: http://www.beta.inegi.org.mx/proyectos/enchogares/especiales/intercensal/default. $\mathrm{html}=1(2017)$

4. Dantzig, R.: The truck dispatching problem. Management science, pp. 80-91 (1959)

5. INFORMADOR: http://www.informador.com.mx/economia/2015/622072/6/guadalajarala-primera-ciudad-inteligente.htm (2015)

6. JALISCO: https://datos.jalisco.gob.mx/dataset/catalogo-georreferenciado-de-terminalesmibici (2015)

7. Jia, S. et al.: Models for Effective Deployment and Redistribution of Bicycles Within Public Bicycle-Sharing Systems. Operations Research 201361(6), pp. 1346-1359 (2013)

8. Méndez, L. et al.: Multi-agent System for the Control and Monitoring of Shared Bicycle Fleets. International Symposium on Ambient Intelligence (2017)

9. Cashous, W., et al.: Ant Colony Optimization Applied to the Bike Sharing Problem. (2015)

10. Longbiao, Ch. et al.: Bike sharing station placement leveraging heterogeneous urban open data. (2015)

11. Matlab: https://www.mathworks.com/matlabcentral/profile/authors/3883690-sas-wahidhamzah (2016)

12. Cossio-Franco, E., Hernández-Aguilar, J., Ochoa-Zezzatti, A., Ponce-Gallegos, J. Comparison between instances to solve the CVRP. International Journal of Combinatorial Optimization Problems and Informatics, 9(2), pp. 41-54 (2018)

13. Ponce, J.C., Recio, A., Ochoa, A., Ornelas, F., Padilla, A., Torres, A.: Implementación de un algoritmo de colonia de hormigas en CUDA aplicado al problema de ruteo de vehículos in Aplicaciones Modernas de Optimización, la experiencia entre cuerpos Académicos (2014) 